\title{
CONTRATOS NA INTERNET E A TRANSNACIONALIZAÇÃO DOS CONSUMIDORES
}

Yhon Tostes ${ }^{1}$

Recebido em 05/08/2021

Aceito em 11/09/2021

\section{RESUMO}

$\mathrm{O}$ artigo discorre sobre a necessidade de um maior diálogo interdisciplinar entre Direito e Economia, especialmente agora quando vivemos uma Pandemia do Coronavírus COVID-19. Apresentaremos o tema na área de contratos bancários e os fundamentos da análise econômica do direito, bem como, a utilização da nova lei de declaração de direitos de liberdade econômica e de livre mercado nas decisões judiciais no Brasil.

PALAVRAS-CHAVE: Pandemia. Economia. Coronavírus COVID 19. Análise Econômica do Direito. Revisão Contratual. Contratos bancários. Liberdade econômica. Livre Mercado.

\section{PANDEMIC AND ECONOMY: DIALOGUE WITHOUT RHYME IN BRAZIL}

\section{ABSTRACT}

The article discusses the need for a greater interdisciplinary dialogue between Law and Economics, especially now when we live in a COVID-19 Coronavirus Pandemic. We will present the topic in the area of bank contracts and the fundamentals of Law and Economics as well as the use of the new law on the declaration of economic freedom and free market rights in judicial decisions in Brazil.

Keywords: Pandemic. Economy. Coronavirus COVID 19. Law and Economics. Contractual Review. Bank contracts. Economic freedom. Free Market.

\section{INTRODUÇÃO}

Vivemos um momento histórico epidemiológico extremamente complexo com a Pandemia do Coronavírus COVID- 19.

Por mais que seja o assunto do momento, há uma sensação geral de que isso jamais aconteceu e nunca a humanidade experimentou um impacto tão colossal em suas estruturas sociais.

\footnotetext{
${ }^{1}$ Doutorando em Direito pela Universidade do Vale do Itajaí; Mestre em Ciências Jurídicas pela Universidade do Vale do Itajaí, com parte dos créditos realizados na Universidade de Alicante, Espanha; Pós-graduado pela Escola Superior da Magistratura de Santa Catarina; Graduado em Direito pela Universidade Federal de Santa Catarina; Coordenador da Escola Superior da Magistratura, extensão de Joinville; Juiz de Direito desde 1994 e atualmente Juiz Eleitoral da 96ª ZE de Joinville-/SC; e-mail:yhon.tostes@gmail.com.
} 
Embora seja um momento bastante complexo e diferenciado, também não podemos dizer que jamais realmente sofremos algo semelhante.

Diamond (2013, p. 164), em sua obra publicada originalmente em 1997, agraciada com os Prêmios Pulitzer e o Aventis de melhor livro científico do ano seguinte, já bem advertia que:

Os principais assassinos da humanidade ao longo de nossa história recente, varíola, gripe, tuberculose, malária, peste bubônica, sarampo e cólera, são doenças infecciosas que se desenvolveram de doenças de animais, embora a maioria dos micróbios responsáveis por nossas próprias epidemias agora esteja, paradoxalmente, quase restrita aos seres humanos. Por terem sido as maiores assassinas das pessoas, as doenças também moldaram de forma decisiva a história. Até a Segunda Guerra Mundial, uma quantidade maior de vítimas morreu por causa de micróbios trazidos com a guerra do que dos ferimentos das batalhas.

Em que pese a aparente histeria coletiva inicial provocada pelo excesso de informações sobre a nova doença, consequências ainda desconhecidas e o distanciamento social, logo surgiram também as questões mais comezinhas da vida humana, dentre elas, as econômicas.

O falso dilema da dualidade entre a proteção da vida e da economia surgiu com retóricas fanáticas e vociferações de oportunistas diante de uma massa atônita e gaguejante sem saber que rumo tomar.

E grandes dúvidas pairam no ar.

Na espera pública: As políticas econômicas e sociais da atualidade ainda funcionam? Os agentes políticos, administradores e membros do Judiciário estão ou não perdidos diante dos conflitos há muito experimentados pela sociedade?

$\mathrm{Na}$ esfera privada: $\mathrm{O}$ meu empreendimento ou minha vida orçamentária está indo mal? Consigo arcar com os financiamentos e negócios anteriormente assumidos diante dos problemas com orçamento reduzido e desemprego crescente?

A resposta tem sido quase unânime a todas essas indagações: Culpa a pandemia! Culpa o sistema! Somos todas vítimas e nada podemos fazer!

Giglioli (2016, p. 19) diz que:

A vítima é o herói do nosso tempo. Ser vítima dá prestígio, exige atenção, promete e promove reconhecimento, ativa um potente gerador de identidade, direito autoestima. Imuniza contra qualquer crítica, garante inocência para além de qualquer dúvida razoável. Como poderia a vítima ser culpada, ou melhor, responsável por alguma coisa? Não fez, foi feito a ela. Não age, padece. Na vítima, articulam-se ausência e reivindicação, fragilidade e pretensão, desejo de ter e desejo de ser. Não somos o que fazemos, mas o que sofremos, o que podemos perder, aquilo que nos privaram.

Nossa proposta é manter distância dessa vitimização que nada resolve para além do palco dos rasos discursos políticos, bem como, ter especial cuidado para não apontar para 
soluções miraculosas na base de exageradas interpretações da legislação consumerista, ou pior ainda, o desvirtuado "CDC" (algo como uma "Codificação do Direito do Coitadinho"), que em cima de retóricas principiológicas acaba muitas vezes pendendo para respostas desconsiderando a necessidade de manutenção do enforcement contratual, a lógica do mercado e o funcionamento da economia.

\title{
1 ESPECTRO POLÍTICO E MUNDIAL
}

Importante realizar uma singela visão de como as coisas estão sendo tratadas pelas nações desenvolvidas e o atual momento brasileiro.

Aqui experimentamos um estilo teatral presidencial com frases de efeito do tipo:

\begin{abstract}
'O mundo todo está sofrendo' (27/02); 'Está superdimensionado o poder destruidor deste vírus' (09/03); 'Esse vírus trouxe uma certa histeria e alguns governadores, no meu entender, estão tomando medidas que vão prejudicar e muito a nossa economia.' (17/03); 'Depois da facada, não vai ser uma gripezinha que vai me derrubar' (20/03); 'O que estão fazendo com o Brasil, alguns poucos governadores e alguns poucos prefeitos, é um crime. Eles estão arrebentando com o Brasil. (...). Outros vírus mataram bem mais do que este e não teve essa comoção toda.' (25/03); 'O vírus está aí. Vamos ter que enfrentá-lo, mas enfrentar como homem, porra. Não como um moleque. Vamos enfrentar o vírus com a realidade. É a vida. Todos nós iremos morrer um dia.' (29/03); 'E daí? Lamento. Quer que eu faça o quê? Eu sou Messias, mas não faço milagre' (28/04). (VANNUCHI, 2020, p. 1).
\end{abstract}

Ao contrário do Brasil, na União Europeia vemos um posicionamento institucional mais sério e em consonância com o momento que a humanidade experimenta:

\begin{abstract}
A propagação do vírus COVID-19 representa um risco dramático para a saúde e a vida de nossos cidadãos, mas também levará a choques sem precedentes para a economia e o emprego na Europa. O surto de COVID-19 exige respostas rápidas dos Estados-Membros e ação conjunta imediata e inovadora das instituições europeias e dos Estados-Membros para combater outra crise econômica profunda e prolongada após a pandemia da saúde. (EUROPEAN PARLIAMENT, 2020, p. 1).
\end{abstract}

Fica claro que, desde o início, no Velho Continente houve uma preocupação conjunta com a Pandemia, e mesmo diante de um cenário epidemiológico desconhecido e preocupante, já havia impulsionamento institucional buscando respostas eficientes para a proteção da vida de todos num primeiro momento e da saúde financeira individual e dos Estados na sequência, após cessar a calamidade.

Em Portugal, no início da crise, o Parlamentou editou o Decreto-Lei n. 10-J/2020, em 26 de março de 2020, tendo como justificativa:

[...] As consequências para a economia exigem a adoção de medidas urgentes tendo em vista a proteção das famílias portuguesas, em matéria de crédito à habitação

Ponto de Vista Jurídico | Caçador | v.10|nº 2 | p. 45 - 62 | jul./dez. 2021 
própria permanente, e das empresas nacionais para assegurar o reforço da sua tesouraria e liquidez, atenuando os efeitos da redução da atividade económica. Os empresários em nome individual, as instituições particulares de solidariedade social, as associações sem fins lucrativos, bem como as demais entidades da economia social são também abrangidos por este regime de proteção. O sistema financeiro tem um especial dever de participação neste esforço conjunto pela sua função essencial de financiamento de qualquer economia. Neste período de incerteza e complexidade, todos os agentes, públicos e privados, são convocados para garantir a sustentabilidade da nossa economia, dos rendimentos dos nossos cidadãos e das nossas empresas. Nestes termos, é aprovada uma moratória, até 30 de setembro de 2020, que prevê a proibição da revogação das linhas de crédito contratadas, a prorrogação ou suspensão dos créditos até fim deste período. Garante-se a continuidade do financiamento às famílias e empresas e previne-se eventuais incumprimentos resultantes da redução da atividade económica.

No Brasil, vide TJDFT (2020), além de duas emendas constitucionais, tivemos uma profusão de edição de leis (em número de 27, sendo a última a Lei n. 14.031, de 28/07/2020); Leis Complementares (duas, sendo a última a de n.173, de 27/05/2020); Medidas Provisórias (50, a última a MP n. 9992, de 16/07/2020) e mais Decretos (30, o último de Dec. N. 10.422, de 13/07/2020), sem contar com resoluções, portarias e instruções.

Sem dúvida, até o momento, a mais importante atuação legislativa foi a Lei n. 14.010, de 10 de junho de 2020, que "dispõe sobre o Regime Jurídico Emergencial e Transitório das relações jurídicas de Direito Privado (RJET) no período da pandemia do corona vírus (COVID19)", mas que já vem sendo alvo de críticas, como as do professor titular de Direito Civil da UERJ, Anderson Schreiber (2020 apud CRUZ, 2020, p. 1):

\begin{abstract}
Os vetos acabaram esvaziando bastante o projeto de lei. São vetos baseados, em linha geral, na ideia de que o legislador deve interferir o menos possível, mesmo diante desse cenário de emergência. É uma questão de visão ideológica do governo, que privilegia o liberalismo econômico. (...). Como resultado, a lei traz um pouco mais de segurança jurídica, mas poderia trazer mais. Com o esvaziamento que ela sofreu por meio dos vetos, o Judiciário continua tendo um papel muito intenso e sem ter parâmetros na lei para atuar. A falta de parâmetros sempre aumenta a insegurança e a imprevisibilidade, o que estimula as pessoas a litigarem (abrirem processos na Justiça).
\end{abstract}

No meio desse dilema existencial, social e inegavelmente econômico, e diante do vácuo de lideranças políticas consolidadas pela história com ética e republicanismo, mais uma vez, o Judiciário acaba sendo chamado para mediar os conflitos que surgem, pois, as soluções legislativas e políticas apresentadas não tem estado à altura do problema enfrentado.

Isso é tão evidente, que o Presidente do STF, Min. Dias Toffoli, na abertura do Congresso Digital da $\mathrm{OAB}$, anotou que:

É fundamental que o Judiciário atue, mas que também tenhamos atuação com prudência e autocontenção para que não substituamos aqueles que têm o poder legítimo da democracia para estabelecer políticas públicas necessárias ao combate à pandemia. (TOFFOLI, 2020 apud VITAL, 2020, p. 1). 
O Ministro Toffoli ainda enfatizou o diálogo com demais ramos da ciência, em especial da saúde e da economia, anotando sobre esse último que "Devemos permanecer unidos na busca por soluções para a superação da crise e que recoloque o país na trilha do desenvolvimento econômico e social" e "Quando a política falha, a parte jurídica vem na defesa do cumprimento dos mandamentos constitucionais" (TOFFOLI, 2020 apud VITAL, 2020, p. 1).

\section{DA ATUAÇÃO DA JUSTIÇA BRASILEIRA NA ÁREA DE CONTRATOS BANCÁRIOS}

Somos conhecidos como um país com problemas na recuperação de crédito, e da excessiva judicialização, como anotam Cooter; Schäfer (2017, p. 140):

\footnotetext{
O Banco mundial identificou quarenta países onde aparatos legais permitem devedores driblar o processo de execução. No Brasil, por exemplo, o direito proíbe o credor de tomar suas garantias sem ordem judicial, o que faz a coleta de débitos se tornar custosa. Em contrapartida, um credor na Alemanha pode reaver as garantias do devedor em questão de semanas sem um procedimento judicial.
}

Diante da abrangência do tema, pretendemos fazer um recorte na área da revisão de contratos bancários.

O que de fato se pode esperar da Justiça diante de negócios entabulados antes ou durante a Pandemia?

Qual a "visão social” que se deve esperar dos juízes?

Existe realmente alguma necessidade-utilidade de utilização da via judicial para remodelar os contratos desse período?

Como ninguém deve partir de um grau zero de compreensão, deixamos claro que nossa abordagem se dará com a análise econômica do contrato.

Entende-se o contrato como um meio jurídico facilitador de produção e circulação de riquezas e a Justiça tendo como missão maior o seu cumprimento e a garantia dos direitos de propriedade visando a fomentar o crescimento econômico e social.

Parece óbvio que precisamos de contratos. Mas na prática as coisas não são assim tão simples, bastando ver a profusão de teorias que existem sobre o tema.

Num mundo em que as pessoas o tempo inteiro estão realizando trocas de bens e serviços é imprescindível que haja cooperação e para isso que servem os contratos, contudo, 
nem sempre isso é possível pois existem falhas de mercado (racionalidade limitada, assimetria informacional, externalidades etc.).

Por isso existe a necessidade de mecanismos jurídicos para lidar com as lacunas existentes nos pactos e até mesmo oportunismos dos agentes envolvidos.

Mas por que nós simplesmente não temos apenas o Judiciário lendo os contratos e executando-os nos termos literais?

Friedman (2000, p. 147), de forma bem objetiva, responde essa questão assim:

There are at least three answers. The first is that courts may not wish to enforce contracts as written because they may believe that they know better than the parties what the terms should have been. A second is that even if you are willing to enforce the contract as written, you still have to decide whether a contract exists and what its terms are, questions about which the parties may sometimes disagree.

A third reason is that even if everybody agrees that a contract exists and should be enforced, and everyone agrees what it says, contracts never say enough. There is not enough fine print in the world to cover every possible contingency. Real-world contracts cover some contingencies, typically ones the drafters think likely to occur, but leave gaps to be filled in by the court. ${ }^{2}$.

Não deve existir algum contrato redigido em qualquer lugar do mundo que tenha efetivamente previsto essa pandemia e antecipado soluções e criado anteparas para evitar inexecução e inúmeros problemas de cooperação entre credores e devedores.

Nesses momentos, é preciso muita serenidade para ter a lei como guia inafastável, não permitindo que o foco num caso individual tisne a visão do todo e suas inegáveis consequências, parafraseando aquela frase famosa que adverte que enquanto observamos apenas os galhos (conflito individual), a floresta inteira está pegando fogo (o sistema econômico ou social atingido igualmente pela pandemia).

Aliás, até Posner (2010, p. 55), Juiz Federal aposentado nos EUA, fundador da Escola de Chicago e um dos ícones da Law \& Economics, lembra que juízes não são seres oniscientes, ou seja, "ser capaz de determinar que decisão judicial teria as melhores consequências em termos globais exigiria o tipo de poderes de raciocínio divino que os pragmatistas ridicularizam como sendo a ilusão dos platonistas.".

\footnotetext{
2 Tradução livre: "Existem pelo menos três respostas. A primeira é que os tribunais podem não desejar impor contratos conforme estão escritos porque podem acreditar que sabem melhor do que as partes quais deveriam ser os termos. Uma segunda é que, mesmo se você estiver disposto a fazer cumprir o contrato como está escrito, ainda precisará decidir se existe um contrato e quais são seus termos, questões sobre as quais as partes às vezes podem discordar. Uma terceira razão é que, mesmo que todos concordem que um contrato existe e deva ser cumprido, e todos concordem com o que diz, os contratos nunca dizem o suficiente. Não há entrelinhas suficientes no mundo para cobrir todas as contingências possíveis. Os contratos do mundo real cobrem algumas contingências, geralmente aquelas que os redatores pensam que provavelmente ocorrerão, mas deixam lacunas a serem preenchidas pelo tribunal".
} 
Igualmente pertinente a visão apresentada por Rosa; Guasque (2020, p. 1), ao dizerem que:

O atual panorama de pandemia, medo, incerteza e crise econômica, constitui um cenário propício ao aumento expressivo da judicialização de questões relativas ao mercado de crédito. Em apreço à imprescindível segurança jurídica, seria bem-vindo que o Poder Judiciário balizasse a sua atuação em prestígio às regras e ao âmbito de competência adstrito a cada um dos Poderes da República. Decisões de vanguarda vêm demonstrando que a politização do Poder Judiciário segue permeando a tomada de decisão judicial, a saber, 'a tentativa do juiz de proteger certos grupos sociais percebidos como sendo mais fracos do que a outra parte no litígio, desconsiderando a lei ou o contrato em prol de um intento de justiça social'.

\section{DAS CONSEQUÊNCIAS DA AUSÊNCIA DE AUTOCONTENÇÃO DOS JUÍZES FRENTE AS AÇÕES REVISIONAIS DE CRÉDITO BANCÁRIO}

É frequente encontrar o repertório pretoriano indicando ações bancárias em que se percebe que alguém ao se sentir desconfortável com algum negócio de crédito, entoa mantras genéricos sobre ofensa à "justiça social", "função social do contrato" e, especialmente agora, levanta a tese de "onerosidade excessiva por conta da pandemia".

Ao final, o pedido judicial é recheado com mais apelos consumeristas, tudo de qualquer jeito e sem a menor consideração que toda ação tem requisitos extrínsecos e intrínsecos que não foram abandonados pelo já não tão novo Código de Processo Civil, conforme está preceituado nos artigos 319 a 321 do citado diploma instrumental.

Apenas exemplificando de forma direta:

[...] nem se fale em inversão do ônus da prova, já que a instrução da peça vestibular com o contrato celebrado importaria em delimitação do pedido, feito de forma genérica e inadmissível. [...]. Muito menos afirmar genericamente que existe algo de errado, que poderá ser apurado em perícia. Constitui o que se convencionou chamar de 'metralhadora giratória'. A demanda judicial não pode ser uma aventura jurídica. Há de conter postulações precisas, viabilizando o exercício do direito de defesa. Nem a alegação de que o relacionamento existente tem características de consumo aproveita à autora, pois o Código de Defesa do Consumidor exige um mínimo de credibilidade na postulação. (TJSP, Ap. Civ. n 994.06.147073-6, Rel. Des. Sebastião Garcia, j. 06/05/2010).

E:

[...] PETIÇÃO INICIAL QUE EFETIVAMENTE CONTÉM IMPUGNAÇÕES GENÉRICAS SEM APONTAR, ESPECIFICAMENTE, AS CLÁUSULAS ABUSIVAS, TAMPOUCO O VALOR INCONTROVERSO DA DÍVIDA. DEMANDANTES, ADEMAIS, QUE CONSIGNAM EXPRESSAMENTE DESCONHECEREM O CONTEÚDO DOS PACTOS, AOS QUAIS SUPOSTAMENTE NÃO TIVERAM ACESSO. PRETENDIDA INVERSÃO DO ÔNUS DA PROVA À LUZ DO CÓDIGO DE DEFESA DO CONSUMIDOR, E EXIBIÇÃO INCIDENTAL DE DOCUMENTOS PELA PARTE CONTRÁRIA, COMO FUNDAMENTOS PARA AFASTAR A EXIGÊNCIA DE QUE, JÁ NA PETIÇÃO INICIAL, O AUTOR ESPECIFIQUE AS ABUSIVIDADES CONTRATUAIS E QUANTIFIQUE O VALOR A SE CONTROVERTER.

Ponto de Vista Jurídico | Caçador | v.10| nº 2 | p. 45 - 62 |jul./dez. 2021 
IMPOSSIBILIDADE. PLEITO DE APRESENTAÇÃO DOS CONTRATOS QUE, POR SI SÓ, NÃO AUTORIZARIA OS REQUERENTES A COMPLEMENTAREM A CAUSA DE PEDIR E OS PEDIDOS DEPOIS DE APRESENTADA A CONTESTAÇÃO. INVERSÃO DO ÔNUS PROBATÓRIO QUE NÃO DISPENSA A PARTE INTERESSADA, MESMO NA CONDIÇÃO DE CONSUMIDORA, DE, ANTES DE PROPOR A DEMANDA, CONHECER O CONTEÚDO DOS CONTRATOS QUE PRETENDE REVISAR, NO INTUITO DE, QUANDO DO AJUIZAMENTO, ESPECIFICAR AS CLÁUSULAS CONTROVERTIDAS E INDICAR O MONTANTE INCONTROVERSO. (...).”. (TJSC, Ap. Civ. n. 030187292.2015.8.24.0038, de Joinville, rel. Des. Luiz Zanelato, ${ }^{\text {a }}$. C. Dto. Com., j. 16-042020).

Tanto é verdade, que já dito expressamente que

[...] O desfile de teses jurídicas adornadas com densas citações doutrinárias e jurisprudenciais não supre, de forma alguma, a exata e precisa descrição dos fatos da vida, dos contornos da divergência surgida na relação social ou contratual concreta, reveladores da causa de pedir, pois neles está o manancial fático sobre o qual se debruçará o julgador para dizer o direito, solucionar o conflito e buscar a máxima justiça e pacificação social. [...] (TJSC, Ap. Civ. n. 0304527-66.2017.8.24.0038).

Esse caminho trágico gerou tantas consequências negativas que a Lei 13.655/18, ao modificar o Dec-lei 4.657/42 (Lei de Introdução às normas do Direito Brasileiro - LINDB), em seu artigo 20, vedou expressamente a utilização de argumentos retóricos ou princípios lógicos sem que seja feita uma análise prévia e detida dos fatos e de suas consequências práticas das decisões judiciais, insurgindo-se fortemente contra o vezo de utilização de valores jurídicos abstratos, expressões de conteúdo aberto e genéricas (à semelhança de "abuso", "justiça social”, “onerosidade excessiva", etc.) e sem observar os resultados para todo o restante dos consumidores que podem e serão atingidos por via reflexa, pois os custos das decisões judiciais, via de regra, não são internalizados pelos fornecedores de bem ou serviços, muito pelo contrário. Já diziam os ingleses: "Não há almoço grátis!".

É preciso resistir e combater essas vitimizações acobertadas por belas expressões travestidas como princípios, sendo pertinente citar novamente Giglioli (2016, p 32), quando diz que:

Sob os despojos de uma moral universal, de baixo custo e altamente utilizável porque não problemática, o credo humanitário é na verdade uma técnica, um conjunto de dispositivos que disciplinam o tratamento das palavras, das imagens sabiamente articuladas em ícones e didascálias, da reações emotivas impostas aos espectadores: esterilização kitsch, sensacionalismo redutivo, naturalização vitimária de populações inteiras.

Sobre isso, Giglioli (2016, p 144) conclui que:

Enfim, a vítima garante verdade. A vítima por definição está na verdade. Não precisa desconfiar de si. Não precisa levar em conta e interpretar nada. Não lhe tocam os escrúpulos com os quais um século e tanto de hermenêutica da suspeição escrutou o nexo inquietante entre verdade e poder. 
Ou seja, o operador do direito não pode se deixar levar por retóricas vitimistas independente da ideologia que os compreenda, devendo manter-se fiel à realidade apresentada nos autos processuais e a legislação que regula a pretensão. Ciência, inclusive a jurídica, se faz com base em evidências concretas, não com "achismos" sobre política, economia, contabilidade, psicologia, sociologia ou saúde pública.

Kirchner (2008 apud SILVA NETO, 2013, p. 99), ao esclarecer a possibilidade da revisão judicial de contratos lembra que

[...] 'o direito à renegociação não beneficia somente o devedor com a permissão da extinção do vínculo e o controle dos efeitos da mora, mas também o credor, que usufrui das vantagens de um contrato reequilibrado, especialmente através da maximização da possibilidade de satisfação de seu crédito, que em muitos casos estaria sensivelmente comprometido com a própria configuração da mora'.

Na sequência, adverte que a análise dos requisitos "deve ser feita de forma cautelosa e prudente e, se existir dúvida quanto à existência dos requisitos legais, o contrato deve ser preservado" (KIRCHNER, 2008 apud SILVA NETO, 2013, p. 99).

E a visão dos custos da judicialização e suas consequências não podem ser ignoradas, como anota Galdino (2005, p. 230):

O reconhecimento dos custos estimula o exercício responsável dos direitos pelas pessoas, o que nem sempre ocorre quando o discurso e a linguagem dos direitos simplesmente fingem ignorar os custos, pois a promessa dos direitos absolutos, além de criar expectativas irrealizáveis, promove o exercício irresponsável e muitas vezes abusivos dos direitos.

Em seu livro sobre a importância das instituições, o Nobel de Economia, North (2018, p.100-101), diz que:

\begin{abstract}
A incapacidade das sociedades de fomentar uma execução de contratos eficaz, com baixo custo, é a fonte mais importante tanto da estagnação histórica como do subdesenvolvimento contemporâneo no Terceiro Mundo. (...). No contexto de um mundo pautado pela maximização da riqueza, em que há custos de mensuração elevados e nenhuma forma de imposição de cumprimento é possível, os ganhos com trapaças e descumprimento de tratos excedem os ganhos com procedimento cooperativo.
\end{abstract}

Há que se ter em mente as externalidades positivas e negativas que estão envolvidas na modificação do negócio jurídico atingido pelas decisões judiciais proferidas no âmbito de um pedido revisional.

Lembra-se que "externalidades", no sentido econômico, de forma geral, são os efeitos da atividade ou relação econômica que incide sobre terceiros aumentando o seu bem estar (positivas) ou diminuindo (negativas). 
Destarte, as leis e o Judiciário podem e devem facilitar a redução dos custos de transação ajudando a equilibrar os negócios de crédito com limites claros e identificando as responsabilidades de cada parte na elaboração de contratos bem redigidos pautados pela boa-fé e observância do regramento legal e com estímulos de cooperação mútua e de fácil execução.

Na linha de raciocínio de Cooter; Ulen (2010), os custos de transação são os custos das trocas ou comércio e são três os seus elementos: os custos de busca; os custos de negociação e os custos de execução.

Os custos de busca são aqueles para a realização do negócio, ou seja, as regras de distribuição de preço, qualidade e análise dos interessados na venda e compra objeto da transação, gerando variáveis como custos mais altos na compra ou venda de produtos especiais e mais baixos quando são comuns no mercado.

Os custos de negociação são sobre o comportamento dos agentes econômicos e as reais intenções e limites que eles possuem na relação compra e venda, sendo um bom exemplo os contratos. Em geral quando as informações estão disponíveis para todos os agentes e sabem os valores de intimidação e cooperação isso baixa os custos e, ao revés, quando essas informações são privadas, ou seja, apenas uma das partes conhece total ou parcial esses valores os custos de transação são elevados.

Os custos de execução têm a ver com o tempo para se fazer cumprir o negócio e a indenização por eventual prejuízo por descumprimento das obrigações anteriormente avençadas. Por conseguinte, os custos de execução são baixos quando as violações do negócio são fáceis de monitorar e é barato aplicar as sanções pelo incumprimento. Já nos casos em que o monitoramento é complexo e o sistema de recuperação dos prejuízos é ineficiente ou dispendioso os custos de execução são elevados.

Por isso, entendemos que o Judiciário deve adotar uma clara postura de autocontenção (self restraint) evitando intervir excessivamente nos contratos movidos por princípios abstratos em que os conceitos morais substituem as regras econômicas do mercado de crédito que é livre e não deve ser regulado por sentença judicial de forma casuística e nem alvo de judicialização da política econômica.

É preciso ter em conta que estamos diante de um "choque simétrico" na economia causado pelo Covid-19, ou seja, que afetou não apenas um empresário ou segmento específico, mas também a todos os setores econômicos, razão pela qual as soluções individualizadas serão extremamente míopes e afetarão negativamente todo o resto da coletividade. Economia trabalha em rede, com intrincadas conexões, não é uma ilha isolada. 
Essa coordenação não se deve dar através de políticas judiciárias ou por decisões judiciais, mas através do Governo Central, que tem a missão constitucional de liderar esse processo político-econômico diante das ferramentas e dados que possui. Em especial, por meio do Banco Central (BACEN) e do Ministério da Economia e sua interação com o Parlamento para construção de um novo design legislativo na seara do direito bancário visando ao enfrentamento diferenciado para esse momento ímpar.

É preciso ter a sensibilidade para aceitar que é extremamente difícil e complexo calcular de forma correta as consequências que decisões judiciais podem gerar no mercado de crédito e obter dados compreensíveis para gente de fora da área especializada que possam nortear uma ação revisional.

Todavia, as decisões distantes de fundamentos e dados econômicos afetam a livre concorrência e o mecanismo de preços, pois não se pode acreditar que sentenças não produzem consequências e focar apenas no caso isolado e não no conjunto delas, que são uma externalidade quase invisível, mas com efeitos concretos.

Timm, ex Secretário Nacional do Consumidor (SENACON) e o Prof. Bicca Machado, já disseram que:

\begin{abstract}
Não é flexibilizando o contrato, protegendo eventualmente um hipossuficiente que, necessariamente, gerar-se-á socialmente maior riqueza e consequentemente maior equilíbrio no seio das relações sociais. Nesse sentido, a função social do contrato, como roupagem jurídica de operações econômicas, não é a relativização do pacta sunt servanda, mas a instrumentalização das trocas, onde quem ganha é a coletividade. E paradoxalmente, na maioria das vezes, a coletividade ganha quando o contrato é cumprido e os custos de um eventual inadimplemento não são redistribuídos aos não participantes da relação !. [...] a opção por um modelo que respeite o mercado (e os institutos a si tão caros, como a propriedade, contratos, etc.) é a mais eficiente socialmente, e a que, portanto, melhor atende à função social do Direito. (TIMM; MACHADO, 2006, p. 1).
\end{abstract}

Aliás, vale realçar que a questão da observância dos "custos de transação" não é invenção doutrinária dos adeptos da "Law and Economics", mas algo claramente presente na Lei n. 13.874, de 20 de setembro de 2019, que instituiu a declaração de direitos de liberdade econômica e estabeleceu garantias de livre mercado, gerando um norte bem claro no tocante à interpretação contratual, verbis:

$\S 1^{\circ} \mathrm{O}$ disposto nesta Lei será observado na aplicação e na interpretação do direito civil, empresarial, econômico, urbanístico e do trabalho nas relações jurídicas que se encontrem no seu âmbito de aplicação e na ordenação pública, inclusive sobre exercício das profissões, comércio, juntas comerciais, registros públicos, trânsito, transporte e proteção ao meio ambiente.

$\S 2^{\circ}$ Interpretam-se em favor da liberdade econômica, da boa-fé e do respeito aos contratos, aos investimentos e à propriedade todas as normas de ordenação pública sobre atividades econômicas privadas. (Parágrafos do art. $1^{\circ}$., da Lei 13.874/2019). 
A opção legislativa é clara sobre a liberdade no exercício das atividades econômicas (dentre eles se incluem os contratos bancários) e a autocontenção que o Estado (Juiz) deve ter ao intervir:

Art. $2^{\circ}$ São princípios que norteiam o disposto nesta Lei:

I - a liberdade como uma garantia no exercício de atividades econômicas;

[...]. III - a intervenção subsidiária e excepcional do Estado sobre o exercício de atividades econômicas;

Art. $3^{\circ}$ São direitos de toda pessoa, natural ou jurídica, essenciais para o desenvolvimento e o crescimento econômicos do País, observado o disposto no parágrafo único do art. 170 da Constituição Federal:

[...]. V - gozar de presunção de boa-fé nos atos praticados no exercício da atividade econômica, para os quais as dúvidas de interpretação do direito civil, empresarial, econômico e urbanístico serão resolvidas de forma a preservar a autonomia privada, exceto se houver expressa disposição legal em contrário.

No capítulo das garantias da livre iniciativa, numa moderna visão de análise econômica do direito, estabelece que é proibido: "V - aumentar os custos de transação sem demonstração de benefícios". (Art.4 ${ }^{\circ}$.).

E, ainda mais, a nova lei efetuou modificações profundas na análise de contratos empresariais, alterando o art. 421 do Código Civil:

\footnotetext{
Art. 421. A liberdade contratual será exercida nos limites da função social do contrato. (Redação dada pela Lei ${ }^{\circ} 13.874$, de 2019)

Parágrafo único. Nas relaç̃os contratuais privadas, prevalecerão o princípio da intervenção mínima e a excepcionalidade da revisão contratual. (Incluído pela Lei $\mathrm{n}^{\circ} 13.874$, de 2019)

Art. 421-A. Os contratos civis e empresariais presumem-se paritários e simétricos até a presença de elementos concretos que justifiquem o afastamento dessa presunção, ressalvados os regimes jurídicos previstos em leis especiais, garantido também que: (Incluído pela Lei $\mathrm{n}^{\circ} 13.874$, de 2019)

I - as partes negociantes poderão estabelecer parâmetros objetivos para a interpretação das cláusulas negociais e de seus pressupostos de revisão ou de resolução; (Incluído pela Lei ${ }^{\circ} 13.874$, de 2019)

II - a alocação de riscos definida pelas partes deve ser respeitada e observada; e (Incluído pela Lei $\mathrm{n}^{\circ} 13.874$, de 2019)

III - a revisão contratual somente ocorrerá de maneira excepcional e limitada. (Incluído pela Lei no 13.874, de 2019).
}

Sob pena de ofensa aos termos da citada legislação, ao se pretender revisar judicialmente um contrato bancário deve haver uma inequívoca demonstração de que não se está aumentando os custos de transação, com ampla e significativa clareza daquilo que se está modificando e qual seu resultado (e esses não são só entre partes, pois as modificações geram externalidades para os usuários do sistema financeiro). E para isso que servem perícias realizadas por equipes interdisciplinares formadas por economistas e contadores, servindo como bom exemplo os laudos de viabilidade econômica e financeira que são apresentados nos processos de recuperação judicial que analisam os dados técnicos sobre a real situação orçamentáriapatrimonial, o cenário micro e macroeconômico atual e as perspectivas futuras (Lei n. 11.101/2005, art. 53). 
Por isso tudo, a atenção aos fundamentos das teorias que tutelam os interesses dos consumidores é de importância capital, com um exercício sério de concreção no tocante que nem tudo que acontece durante a Pandemia do Coronavírus (Covid-19) é caso fortuito ou força maior.

E lembrando Rodrigues Júnior (2006, p. 148): “a teoria da imprevisão é incompatível com formulações teóricas baseadas nos fenômenos de impossibilidade absoluta, impossibilidade relativa, dificuldade de prestação e impossibilidade econômica.”.

Destarte, decisões como a que foi proferida pelo Tribunal de Justiça de São Paulo devem ser vistas com reservas e lastimadas, eis que motivadas apenas na retórica singela da "atual e excepcional conjuntura fático-econômica presenciada, decorrente da pandemia vinculada à Covid-19”(sic), suspendendo a cobrança regular de um empréstimo de 12 milhões contraído em 2018 e com a liberação da garantia de recebíveis do cartão de crédito.”. (BOSELI, 2020, p. $1)$.

Há muito o Superior Tribunal de Justiça vem realçando a importância da análise econômica do contrato e a necessidade de objetividade naquilo que se pretende revisar, diante das externalidades existentes:

RECURSO ESPECIAL. PROCESSUAL CIVIL. CONTRATOS DE FINANCIAMENTO IMOBILIÁRIO. SISTEMA FINANCEIRO DE HABITAÇÃO. LEI N. 10.931/2004. INOVAÇÃO. REQUISITOS PARA PETIÇÃO INICIAL. APLICAÇÃO A TODOS OS CONTRATOS DE FINANCIAMENTO.

1. A análise econômica da função social do contrato, realizada a partir da doutrina da análise econômica do direito, permite reconhecer o papel institucional e social que o direito contratual pode oferecer ao mercado, qual seja a segurança $e$ previsibilidade nas operações econômicas e sociais capazes de proteger as expectativas dos agentes econômicos, por meio de instituições mais sólidas, que reforcem, ao contrário de minar, a estrutura do mercado.

2. Todo contrato de financiamento imobiliário, ainda que pactuado nos moldes do Sistema Financeiro da Habitação, é negócio jurídico de cunho eminentemente patrimonial e, por isso, solo fértil para a aplicação da análise econômica do direito. 3. A Lei n. 10.931/2004, especialmente seu art. 50, inspirou-se na efetividade, celeridade e boa-fé perseguidos pelo processo civil moderno, cujo entendimento é de que todo litígio a ser composto, dentre eles os de cunho econômico, deve apresentar pedido objetivo e apontar precisa e claramente a espécie e o alcance do abuso contratual que fundamenta a ação de revisão do contrato.

4. As regras expressas no art. 50 e seus parágrafos têm a clara intenção de garantir o cumprimento dos contratos de financiamento de imóveis tal como pactuados, gerando segurança para os contratantes.

O objetivo maior da norma é garantir que, quando a execução do contrato se tornar controvertida e necessária for a intervenção judicial, a discussão seja eficiente, porque somente o ponto conflitante será discutido e a discussão da controvérsia não impedirá a execução de tudo aquilo com o qual concordam as partes.

5. Aplicam-se aos contratos de financiamento imobiliário do Sistema de Financiamento Habitacional as disposições da Lei n. 10.931/2004, mormente as referentes aos requisitos da petição inicial da ação de revisão de cláusulas contratuais, constantes do art. 50 da Lei $n$. 10.931/2004. 
6. Recurso especial provido." (STJ. REsp 1163283/RS, Rel. Ministro Luis Felipe Salomão, Quarta Turma, julgado em 07/04/2015, DJe 04/05/2015). [Grifou-se].

Corretos são os comentários de Yeung (2020, p. 85-88) na defesa da lei da liberdade econômica ao trazer o enfoque clássico de Hayek e concluir que a nova legislação oportuniza um ambiente mais seguro para o indispensável crescimento econômico, anotando que na esfera consumerista brasileira:

\begin{abstract}
O que se precisa não são de muletas, mas de provisão ótima do nível de informações para minimizar a assimetria, de condições equiparadas para negociação privada, de eliminação de quaisquer impedimentos para cooperação. [...]. Que a MP 881, agora Lei 13.874 , crie de maneira juridicamente segura um ambiente onde a liberdade econômica seja observada e garantida de vez; só assim para termos mais do que um mero 'espasmo' de crescimento econômico, e talvez algo mais assemelhado a um voo de águia.
\end{abstract}

\title{
CONCLUSÃo
}

Diante disto tudo, entende-se que a par dos fundamentos da teoria da imprevisão, da onerosidade excessiva, do caso fortuito ou força maior e até da teoria dos riscos, a luz da Lei n. 13.874/2019, deverão as ações revisionais deixar claro como pretendem aumentar os custos de transação (no mínimo, a pretensão afeta diretamente o enforcement com o atraso no cumprimento da obrigação), indicando claramente os benefícios reais de eventuais moratórias reclamadas (não basta alegar, há que se ter clareza contábil-econômica se um plano de suspensão de pagamento irá de fato auxiliar a todas as partes envolvidas e, de igual forma, não prejudicar o restante do mercado).

E esperar que os demais poderes (Executivo e Legislativo) cumpram bem sua missão constitucional, utilizando os instrumentos que dispõe (em especial agências reguladoras) e com visão panorâmica realizar a construção de um novo design institucional para conter os efeitos da crise econômica instalada com a pandemia e superar esse complexo momento.

Não é simples, mas a situação exige.

\section{REFERÊNCIAS BIBLIOGRÁFICAS}

BOSELI, André. Cobrança de parcelas de empréstimo bancário e juros é suspensa pelo TJ-SP. Revista Consultor Jurídico, 15/04/2020. Disponível em: <https://www.conjur.com.br/2020abr-15/cobranca-emprestimo-bancario-suspensa-tj-sp>. Acesso em 10 ago. 2020.

BRASIL. Lei n. 13.105, de 16 de março de 2015. Código de Processo Civil. Disponível em: <http://www.planalto.gov.br/ccivil_03/_ato2015-2018/2015/lei/113105.htm>. Acesso em: 10 ago. 2020.

BRASIL. Lei n. 13.655, de 25 de abril de 2018. Inclui no Decreto-Lei no 4.657, de 4 de setembro de 1942 (Lei de Introdução às Normas do Direito Brasileiro), disposições sobre segurança jurídica e eficiência na criação e na aplicação do direito público. Disponível em: 
<http://www.planalto.gov.br/ccivil_03/_ato2015-2018/2018/lei/L13655.htm>. Acesso em: 10 ago. 2020.

BRASIL. Lei n. 13.874, de 20 de setembro de 2019. Institui a Declaração de Direitos de Liberdade Econômica; estabelece garantias de livre mercado; altera as Leis nos 10.406, de 10 de janeiro de 2002 (Código Civil), 6.404, de 15 de dezembro de 1976, 11.598, de 3 de dezembro de 2007, 12.682, de 9 de julho de 2012, 6.015, de 31 de dezembro de 1973, 10.522, de 19 de julho de 2002, 8.934, de 18 de novembro 1994, o Decreto-Lei no 9.760, de 5 de setembro de 1946 e a Consolidação das Leis do Trabalho, aprovada pelo Decreto-Lei $\mathrm{n}^{\circ}$ 5.452, de $1^{\circ}$ de maio de 1943; revoga a Lei Delegada $n^{\circ}$ 4, de 26 de setembro de 1962, a Lei $\mathrm{n}^{\circ} 11.887$, de 24 de dezembro de 2008, e dispositivos do Decreto-Lei $\mathrm{n}^{\circ} 73$, de 21 de novembro de 1966; e dá outras providências. Disponível em: <http://www.planalto.gov.br/ccivil_03/_ato2019-2022/2019/lei/L13874.htm>. Acesso em: 10 ago. 2020.

BRASIL. Lei n. 14.010, de 10 de junho de 2020. Dispõe sobre o Regime Jurídico Emergencial e Transitório das relações jurídicas de Direito Privado (RJET) no período da pandemia do coronavírus (Covid-19). Disponível em:

<http://www.planalto.gov.br/ccivil_03/_ato2019-2022/2020/lei/L14010.htm>. Acesso em: 10 ago. 2020.

BRASIL. Tribunal de Justiça de Santa Catarina. Apelação Cível n. 0301872-

92.2015.8.24.0038, de Joinville, rel. Des. Luiz Zanelato, 1ª C. Dto. Com., j. 16-04-2020.

BRASIL. Tribunal de Justiça de Santa Catarina - TJSC. Apelação Cível n. 030452766.2017.8.24.0038, de Joinville, rel. Des. Luiz Felipe Schuch, Segunda Câmara de Direito Comercial, j. 07-05-2019.

BRASIL. Tribunal de Justiça de São Paulo - TJSP. Apelação Cível n. 994.06.147073-6, Rel. Des. Sebastião Garcia, j. 06/05/2010.

BRASIL. Superior Tribunal de Justiça - STJ. REsp 1163283/RS, Rel. Ministro Luis Felipe Salomão, Quarta turma, julgado em 07/04/2015, DJe 04/05/2015.

COOTER, Robert Dandridge; SCHÄFER, Hans-Bernd. O nó de Salomão: como o direito pode erradicar a pobreza das nações. 1. ed. Curitiba: CRV, 2017.

COOTER, Robert; ULEN, Thomas. Direito e economia. 5. ed. Porto Alegre: Bookman, 2010.

CRUZ, Izabela. Nexo Jornal. Expresso. Como ficou a regulação do direito privado na pandemia. 17/06/2020. Disponível em:

$<$ https://www.nexojornal.com.br/expresso/2020/06/17/Como-ficou-aregula\%C3\%A7\%C3\%A3o-do-direito-privado-na-pandemia>. Acesso em: 04 ago. 2020.

DIAMOND, Jared M.. Armas, germes e aço: os destinos das sociedades. 15. ed. Rio de Janeiro: Record, 2013. 
EUROPEAN PARLIAMENT. Committes. ECON activities in regard to COVID-19.

13/07/2020. Disponível em: <https://www.europarl.europa.eu/committees/en/econ-activitiesin-regard-to-covid-19/product-details/20200624CAN55981>. Acesso em: 10 ago. 2020.

FRIEDMAN, David D. Law's order: what economics has to do with law and why it matters. Princeton University Press, 2000.

GALDINO, Flávio. Introdução à teoria dos custos dos direitos: direitos não nascem em árvores. Editora Lumen Juris: Rio de Janeiro, 2005.

GIGLIOLI, Daniele. Crítica da vítima. Belo Horizonte: Editora Âyné, 2016.

NORTH, C. Douglas. Instituições, Mudança institucional e desempenho econômico. São Paulo: Três Estrelas, 2018.

PORTUGAL. Decreto-Lei n. ${ }^{\circ}$ 10-J/2020 - Diário da República n. $.^{\circ} 61 / 2020,1^{\circ}$ Suplemento, Série I de 2020-03-26. Estabelece medidas excecionais de proteção dos créditos das famílias, empresas, instituições particularesde solidariedade social e demais entidades da economia social, bem como um regime especial de garantias pessoais do Estado, no âmbito da pandemia da doença COVID-19. Disponível em: <https://dre.pt/web/guest/legislacao-consolidada//lc/135710693/202006160100/exportPdf/normal/1/cacheLevelPage?_LegislacaoConsolidada_ WAR_drefrontofficeportlet_rp=indice>. Acesso em: 10 ago. 2020.

POSNER, Richard A. Direito, pragmatismo e democracia. Rio de Janeiro: Forense, 2010.

RODRIGUES JÚNIOR, Otávio Luiz. Revisão judicial dos contratos: autonomia da vontade e teoria da imprevisão. 2. ed. São Paulo: Atlas, 2006.

ROSA, Alexandre Morais da; GUASQUE, Bárbara. As decisões judiciais e a tragédia do mercado de crédito em tempos de pandemia. Migalhas. 27/04/2020. Disponível em: $<$ https://migalhas.com.br//depeso/325572/as-decisoes-judiciais-e-a-tragedia-do-mercadode-credito-em-tempos-de-pandemia>. Acesso em: 28 abr. 2020.

SILVA NETO, Orlando Celso da. Comentários ao Código de Defesa do Consumidor. Rio de Janeiro: Ed. Forense, 2013.

TIMM, Luciano Benetti; MACHADO, Rafael Bicca. Direito, mercado e função social. Revista da Ajuris. Vol. 103 (2006). Disponível em:

"http://works.bepress.com/luciano_benetti_timm/12/". Acesso em: 10 ago. 2020.

TJDFT. Legislação Federal COVID 19 - Coronavírus. Disponível em:

<https://www.tjdft.jus.br/institucional/relacoes-institucionais/legislacao-covid-19-2013coronavirus/legislacao-federal-covid-19-coronavirus>. Acesso em: 03 ago. 2020.

VANNUCHI, Camilo. A pandemia de Covid-19 segundo Bolsonaro: da "gripezinha" ao "e daí?”. 30/04/2020. Disponível em: <https://noticias.uol.com.br/colunas/camilovannuchi/2020/04/30/a-pandemia-de-covid-19-segundo-bolsonaro-da-gripezinha-ao-edai.htm>. Acesso em: 04 ago. 2020. 
VITAL, Danilo. 17/07/2020. Judiciário não pode substituir responsáveis por política pública na epidemia, diz Toffoli. Revista Consultor Jurídico. Disponível em:

<https://www.conjur.com.br/2020-jul-27/toffoli-justica-nao-substituir-responsaveis-politicapublica>. Acesso em: 28 jul. 2020.

YEUNG, Luciana L. Friedrich Hayek, Liberdade Econômica, A MP e a Lei da Liberdade Econômica: Por que é necessária? in Lei de Liberdade Econômica e seus impactos no Direito brasileiro. Coord. Luiz Felipe Salomão, Ricardo Villas Bôas Cueva e Ana Frazão. $1^{\text {a }}$.Ed., São Paulo: Thomson Reuters Brasil, 2020. 